\title{
EN TORNO A UN POSIBLE NUEVO ENFOQUE DE LA ASIGNATURA DENOMINADA DERECHO POLITICO
}

\author{
POR \\ OSCAR ALZAGA VILLAAMIL \\ Catedrático de Derecho Político \\ Universidad Nacional de Educación a Distancia
}

\begin{abstract}
Derecho politico: entre hidra de muchas cabezas y universal comodín; de todo un poco, alternativamente (...).

Nombre usual y oficialmente impuesto a una enseñanza que sus profesores interpretan de manera varia y - a veces- contradictoria.

Probablemente, en ninguna otra de las asignaturas que figuran en el plan de estudios de las Facultades de Derecho, parecen disfrutar sus docentes de una libertad tan libérrima para fijar el contenido y trazar los linderos de su materia.

En efecto, el Derecho político parece no sólo ser ésto o aquéllo, todo en uno. Hasta se podría decir - sin miedo a lo absurdo- que el adefesio jurídico llamado Derecho político es un vertebrado gaseoso.
\end{abstract}

Nicolás Ramiro Rrco ${ }^{1}$

El grado de confusión a que se ha llegado en torno al contenido de nuestra disciplina, tan irónicamente descrito por el que fue gran maestro, en el párrafo que hemos adoptado como pórtico para este artículo, arranca -al menos en parte- de los paradójicos criterios con que se ha concebido esta sufrida asignatura en los sucesivos planes de estudios de nuestras universidades.

Por razones de simple curiosidad, he tenido interés en ver cómo justificó el legislador la mayoría de edad de nuestra disciplina cuando en el Real Decreto de 2 de agosto de 1900 se emancipa el Derecho político del Derecho administrativo. Pues bien, las razones que en la exposición de motivos de esta disposición se nos dan no pueden ser más deliciosas. En primer lugar se alega que nuestra asignatura debe seguir el ritmo de «los progresos verdaderamente asombrosos realizados en los últimos tiempos».

$\mathrm{Y}$ al rectificar el tono, exclusivamente profesional, de la formación que - según se dice- anteriormente se aspiraba a brindar a los alumnos consigna

' Nicolás Ramiro Rico, Breves apuntes criticos para un futuro programa moderadamente beterodoxo del Derecho politico, y de su muy azorante enseñanza, en «Revista Española de la Opinión Pública», núm. 37, 1974, pág. 180. 
argumentos no poco peregrinos: «... al lado de la jurisprudencia - se afirmadebe figurar la política, que comprende las leyes a que se ajusta la acción pública del que gobierna en el régimen de los pueblos, materia de los otros dos poderes, que sólo rudimentariamente se estudia en nuestras universidades, y si acaso esto ha podido bastar en otros tiempos, puesto que al fin y al cabo la política se funda en los principios y reglas que constituyen la jurisprudencia, es a todas luces deficiente en el estado social a que poco a poco nos han ido conduciendo los grandes acontecimientos históricos de la Edad Moderna».

No podemos dejar de confesar que no hemos podido penetrar en el último reducto de la «voluntad de la ley», acaso porque el concepto de «jurisprudencia» y el de «política», que parecen servir de base a tal norma, se hallan tan lejos de las concepciones actuales como lo está la misma idea que mueve al autor del Decreto en cuestión, esto es, «formar hombres que, adornados de los conocimientos de la vida política, investiguen, según las circunstancias, la razón de Estado y la salud del pueblo, y puedan en lo venidero dirigir los destinos de la patria».

Lo que sí puede traslucirse de esta disposición es un latente propósito de contribuir more britannico a que nuestra disciplina proporcione una aristocracia intelectual capaz de gobernar el día de mañana; pero, a decir verdad, mal cabe concebir el empeño, pensamos nosotros, si los discípulos iban a ser adoctrinados para ello en las tesis del secretario florentino o en principios como el de la salus populi, que se enuncia más como tropo retórico que como expresión de un sincero convencimiento.

Por si todo lo anterior no fuese suficientemente oscuro, el Decreto de 1900 estableció como denominación oficial la de «Derecho político español comparado con el extranjero", que se justificaba en esta exposición de motivos, que realmente no tenía desperdicio, por la «solidaridad que por numerosas causas es cada día mayor entre todas las naciones, y el sistema de libertad que en materia de extranjería por todas partes impera».

Numerosas disposiciones posteriores, lejos de delimitar con un mínimo de precisión el ámbito de nuestra asignatura, consagran un totum revolutum en el que cada catedrático se vería obligado a imprimir por su cuenta al programa la dirección que le pareciese más oportuna. Y el título de nuestra disciplina, que no coincide por entero, como es sabido, con la terminología en uso en otros países, no contribuye a esclarecer sustancialmente el objeto de nuestra ciencia, aunque -como contrapartida - ha ofrecido tanto un marco amplio para que el enfoque de nuestros estudios haya podido evolucionar, con suerte realmente no uniforme, a la par que las nuevas corrientes científicas, como un cierto valor estético y tradicional que ha resaltado el profesor Lucas Verdú $^{2}$ en la línea de Pérez Serrano, para quien nuestra terminología es la «más generosa y cumplida» ${ }^{3}$.

A medida que se ha avanzado en el proceso de complejización de nuestra asignatura, diestramente descrito por Giacomo Perticone, su contenido ha

${ }^{2}$ Pablo Lucas Verdú, Curso de Derecho politico, Madrid, 1972, 1 vol., págs. 37-38.

3 Nicolás Pérez Serrano, Las ficciones en el Derecbo constitucional (Discurso leído el día 25 de mayo de 1948, en su recepción pública en la Real Academia de Jurisprudencia y Legislación), Madrid, 1948, pág. 13. 
planteado mayores problemas de lindes, pero sin duda el más arduo y a su vez el más actual es el que se plantea entre Derecho político, Derecho constitucional y ciencia política, que en parte-desde luego, sólo en parte- es prolongación del problema de identidad o distinción entre el Derecho constitucional y la teoría general del Estado, que abordó ya, entre otros, Fischbach ${ }^{4}$, o, en diverso aspecto, de la distinción entre la teoría sociológica y jurídica del Estado, que acuñó con singular agudeza Jellinek ${ }^{5}$.

La más antigua concepción de la ciencia política, que subyacía en las clásicas obras que nos ha legado Grecia y que ha perdurado hasta fines del siglo XIX por su amplitud, cuando es reactualizada hoy, por ejemplo, por Waitz ${ }^{6}$ y por Freund ${ }^{7}$, aboca a la conclusión de que el Derecho constitucional es una simple rama de la ciencia política. No nos parece ésta una afirmación suscribible, porque implica desconocer la dimensión sustancialmente jurídica del Derecho constitucional, para convertirlo en un simple reflejo de factores de otra índole. Aunque no dejamos de reconocer que esta posición goza hoy de un cierto predicamento $y$, en última instancia, es expresión del desinterés, muy generalizado en nuestro tiempo, por los problemas jurídicos. Este desinterés no es sólo producto de una actitud cínica, convencida de «que haya van leyes do quieren reyes», sino también, como se ha dicho con buen criterio, de dos realidades muy de nuestra época: el carácter meramente aparencial que los modelos constitucionales revisten al ser trasplantados a países nuevos, con «culturas políticas» muy disímiles de la del Estado-nación de Occidente, y la tesis, de cuño marxista, que ve en el Derecho una realidad meramente superestructural ${ }^{8}$. Si se aceptasen sin reservas ambas acusaciones contra el Derecho, el Derecho constitucional se mostraría como un simple epifenómeno - por emplear la expresión utilizada al respecto por González Casanova ${ }^{9}-$ y, en última instancia, no cabría ni la construcción de auténticas ciencias normativas en general, ni más en concreto la construcción de una ciencia del Derecho constitucional mínimamente autónoma.

En las antípodas de tal posición encontramos la afirmación de la dogmática alemana tradicional, llevada hasta sus últimas consecuencias por la escuela de Viena, de que el Derecho constitucional ha de ser por entero ajeno a la ciencia política. En consecuencia, en una asignatura de Derecho político no habría lugar alguno para la ciencia política. Kelsen partía de una distinción radical entre el ser y el deber ser (que, dicho sea entre paréntesis, se nos antoja muy discutible desde el punto de vista de la teoría del conocimiento), al efecto de

4 Oskar Georg Fischbach, Derecbo politico general y constitucional comparado, 2.: ed., Barcelona, 1934, pág. 11. Véase también, del mismo autor, Teoría general del Estado, 2." ed., Barcelona, 1922. 16-17.

${ }^{5}$ Georg Jellinek, Teoría general del Estado, Buenos Aires, 1970, págs., entre otras,

- Cfr. Heinrich Triepel, Derecho público y politica, Madrid, 1954.

7 Julien Freund, Pbilosopbie et Sociologie politiques, en «Archives Européens de Sociologies, vol. VIII-1, 1967, pág. 150.

${ }^{8}$ Francisco Rubio Llorente, Nota preliminar a la edición española, en Ekehart Stein, Derecho politico, Madrid, 1973.

9 José Antonio González Casanova, Comunicación bumana y comunidad política. Una aproximación al Derecbo político, Madrid, 1968. 
excluir del Derecho en general y de nuestra disciplina en particular toda ponderación causal en la medida en que se trata de una ciencia normativa ${ }^{10}$. Pese a que Laband había aceptado en alguna medida que la finalidad de una institución puede afectar a su configuración jurídica y, en consecuencia, ser de interés para su estudio " por la escuela de Viena, obsesionada en convertir el Derecho público en una esotérica teoría que no se pudiera contaminar en contacto con la realidad política.

Pero, como exclamó, con razón, Triepel en 1926: «iA dónde hubiésemos llegado de haber estudiado el Derecho canónico sin historia de la Iglesia y el Derecho mercantil o el tributario sin referencia a la economía pública y privada!» Ya Pufendorf se enojaba con los profesores de Derecho público, que estudiaban la Constitución alemana sin conocer las res civiles, esto es, la política. «Son tan aptos para el estudio del Derecho constitucional - decía burlándose- como el asno para la música de arpa» ${ }^{12}$.

Y en la misma línea cabría traer a colación el interrogante que más recientemente formulara Donnedieu de Vabres, cuando se pregunta: «¿Y qué se dirá acaso del civilista que para exponer la reglamentación del divorcio aludiera a los perjuicios sociales del adulterio, que renuncia a la toga roja del jurista para vestir la amarilla del sociólogo?» ${ }^{13}$.

Una tercera dirección científica considera el rótulo «Derecho político» como capaz de albergar en su seno tanto a la ciencia política como al Derecho constitucional. Nos referimos a la posición defendida en España por Lucas Verdú, quien ha sostenido que «para no incurrir en el defecto de yuxtaposición y anarquía temática que caracterizan al Derecho político oficial, preferimos considerar como materia del Derecho político adjetivado dos grandes: sectores: uno de ellos está integrado por la ciencia política en cuanto estudio de los fenómenos que se refieren al fundamento, objetivos, organización y ejercicio del poder político en la sociedad, y el otro sector corresponde al Derecho constitucional en cuanto estudio de las reglas e instituciones jurídicas fundamentales, relativas a la organización y ejercicio del poder político y a los derechos y libertades básicos del ciudadano» ${ }^{14}$.

La posición del profesor Ferrando Badía es en lo sustancial análoga, toda vez que, lejos de admitir la existencia de una antítesis radical entre el Derecho constitucional y la ciencia política, ha sostenido, apoyándose en una afirmación

\footnotetext{
10 Probablemente una de las más lúcidas y brillantes exposiciones que nos ha dejado Kelsen sobre sus tesis al respecto es la que encontramos en su no muy divulgado comentario crítico al libro de Alf Ross, On Law and Justice, 1955, que se puede consultar en la recopilación de trabajos de aquél titulada Contribuciones a la teoria pura del Derecbo, Buenos Aires, 1969; véanse especialmente, págs. 15 y sigs.

${ }^{11}$ Cfr. Laband, Das Staatsrecht des Deutschen Reiches, 5.* ed., 1911.

12 Heintich Triepel, Derecho público y politica, Madrid, 1974, pág. 51.

${ }^{13}$ Donnedieu de Vabres, La science politique contemporaine, en «Revue Française de Science Politique», 1952, pág. 395.

${ }^{14}$ Pablo Lucas Verdú, Curso de Derecbo político, Madrid, 1972, vol. I, págs. 37-38. Véase también manifestación análoga del mismo autor en su obra Principios de ciencia política, 3." ed., Madrid, 1973, vol. I, pág. 104.
} 
de Sánchez Agesta ${ }^{15}$, que cabe una cierta equiparación entre Derecho político y ciencia política ${ }^{16}$.

Finalmente, hemos de referirnos a una posición que no pasa de matizar las últimas que hemos mencionado. Se trata de la defendida por Isaac Ganon, para quien «la ciencia política tiene por objeto la explicación de los hechos políticos, sea la democracia, como en Tocqueville; sea el conflicto o lucha de clases encaminado a la conservación o a la destrucción del Estado, como en Marx; sea la burocracia y la oligarquía, como en Weber o en Michels; sea la clase gobernante o las élites de poder, como en Mosca, Pareto y Mills; sea, para regresar al punto que constituye su tema clásico y siempre presente, las manifestaciones del poder, ya se traduzcan en hechos definidamente políticos, como el Estado, ya en fenómenos aparentemente no políticos, pero capaces de influir políticamente, como los grupos de presión».

A la vez el mismo Ganon nos dice que el Derecho político «tiene por objeto el estudio de las reglas jurídicas relativas a las manifestaciones del poder; se hallen las mismas en la Constitución o en las fuentes sociales, de las cuales esta misma extrae su origen y fundamentación» ${ }^{17}$. De lo que se deduce que para los especialistas en nuestra asignatura la ciencia política es una disciplina auxiliar del Derecho constitucional, de la que podríamos decir que cumple la función de convertir a éste en Derecho político. Conforme a esta concepción, en suma, el estudioso de nuestra disciplina no ha de profundizar necesariamente en toda la temática propia de la ciencia política, sino tan sólo en aquellos de sus problemas que ejerzan un influjo sustancial en la vigencia de la normatividad que aspira a regir la actividad política, para que la profundización de los entresijos del Derecho constitucional siga la trayectoria marcada por el mejor realismo jurídico-político.

Esta tesis que defendemos nos parece afortunada, máxime a la vista de la carencia de un tratamiento autónomo de la ciencia política en nuestras universidades, si se quiere y en alguna medida, con la excepción huérfana de la Facultad de Ciencias.Políticas de Madrid. Confío en que algún día se reconozca en la forma debida que, pese a haber sido desahuciada injustamente la ciencia política de nuestros planes de estudios, se ha podido cultivar en nuestra patria gracias al esfuerzo oportuno y constante que a tal fin han dedicado en los últimos años algunos especialistas de Derecho político, entre los que quizá quepa destacar la labor de los maestros Murillo, Lucas Verdú, Ferrando, Ramírez, Cazorla...

Retornando al hilo de nuestra exposición, creo que es preciso afirmar la trascendencia de eso que desde nuestra perspectiva de juristas, que impartimos enseñanza en una facultad de Derecho, damos en llamar función auxiliar, puesto que es compatible con creer, junto a Burdeau, que el objeto de la ciencia política no tiene por qué ser colocado de suyo en relación de dependencia con respecto al Derecho constitucional. Como dice en frase gráfica el gran maestro

15 Luis Sánchez Agesta, Lecciones de Derecho político, 6." ed., Granada, 1959, pág. 1.

16 Juan Ferrando Badía, Enfoques en el estudio de las ciencias políticas, en «Revista de Estudios Políticos», núm. 187, 1953, págs. 9 a 63.

${ }_{17}$ Isaac Ganon, La política como ciencia autónoma y como sociología, en «Revista de Estudios Políticos», núms. 129-130, pág. 54. 
francés, «la ciencia política no está hecha para amenizar con anécdota la árida exposición de las normas jurídicas» ${ }^{18}$.

Un autor ajeno a nuestra especialidad, pero al que se debe la que es, a mi juicio, la mejor obra sobre Introducción al Derecho, que en los últimos años se haya aportado a la bibliografía española, Angel Latorre ${ }^{19}$, ha sostenido también que la ciencia política ha de ser compañera inseparable del estudio del Derecho político, y lo ha hecho en términos análogos a los empleados por Ganon.

Así, encuadradas en nuestra disciplina tanto el Derecho constitucional como determinadas parcelas de la ciencia política - que desempeñan una «alta función auxiliar»-, estaremos en condiciones de formular un Derecho político auténticamente realista que parta de la premisa de que el régimen político de un pueblo no coincide nunca con la totalidad de los aspectos organizativos descritos en sus leyes constitucionales.

En consecuencia, creemos, con Jiménez de Parga, que nuestra disciplina científica ha de pretender dar a conocer la verdad política de un régimen, y para ello setá una disciplina jurídica, ya que el Derecho es un principio configurador de la política; pero será, además, una disciplina preocupada por el funcionamiento efectivo de las instituciones y por las bases de toda índole que apoyan las distintas soluciones jurídico-políticas ${ }^{20}$. Así, el concepto de «régimen político» se nos eleva al rango de lo que se ha denominado «noción encrucijada» de nuestra disciplina ${ }^{21}$, y ello será así tanto si nos acogemos a la noción de «régimen» acuñada por la escuela francesa, en la línea señalada por Burdeau ${ }^{22}$ y por Duverger ${ }^{23}$, como si nos atenemos al concepto de régimen que nos ha facilitado la dogmática italiana desde Panunzio ${ }^{24}$ y Costamagna ${ }^{25}$ hasta Chiarelli ${ }^{26}$ y Barile ${ }^{27}$, y desde Mortati ${ }^{28}$, Romano ${ }^{29}$ y Martines ${ }^{30}$ hasta

${ }^{18}$ Georges Burdeau, Método de la ciencia política, Buenos Aires, 1964, pág. 142.

19 Angel Latorre, Introducción al Derecho, Barcelona, 1968, pág. 92.

${ }^{2}$ Manuel Jiménez de Parga, Los regímenes políticos contemporáneos, 3." ed, Madrid, 1965, pág. 13. En línea muy similar puede consultarse, José Antonio González Casanova, Comunicación bumana y comunidad política, Madrid, 1968, págs. 210-216.

${ }^{21}$ Juan Ferrando Badía, Enfoques en el estudio de las ciencias políticas, en «Revista de Estudios Políticos», núm. 187 (1973), pág. 32.

${ }_{2}$ Georges Burdeau, Traité de Science politique, París, 1952, vol. IV, pág. 22.

${ }^{23}$ Maurice Duverger, Instituciones políticas y Derecbo constitucional, Barcelona, 1962, página 13. Por su parte Marcel Prelot, siguiendo la dirección mayoritaria de la escuela francesa sobre esta problemática, se ha planteado el aspecto de la transitoriedad de los regímenes políticos, desde una perspectiva fundamentalmente sociológica y conforme a lo que él denomina «la dialéctica del poder y la fuerza». Véase su obra, La ciencia política, 6." ed., Buenos Aires, 1972, págs. 91-193.

24 Sergio Panunzio, Teoria generale dello Stato fascista, 2.: ed., Padua, 1939, pág. 592. Véase también su capítulo IV de la parte V, titulado «Partito, Regime, Stato».

${ }_{25}$ Costamagna, Regime, en «Dizzionario di politica», elaborado por el Partido Nacional Fascista, Roma, 1940, vol. IV, págs. 31-35. En cierta medida las tesis de este autor se encuentran recogidas en el trabajo de Francisco Javier Conde, Representación política (1945), en Escritos y tragmentos políticos, Madrid, 1974, vol. I, págs. 439-455.

${ }_{20}$ Giuseppe Chiarelli, Il concetto di regime nel Diritto pubblico, en «Archivo Giuridico», Módena, 1932, vol. CVIII, fasc. 2, pág. 212.

${ }_{27}$ Cfr. Paolo Biscaretti di Ruffia, Derecho constitucional, Madrid, 1965, pág. 152.

${ }^{28}$ Constantino Mortati, La costituzione in senso materiale, Milán, 1940.

${ }^{29}$ Santi Romano, Principii di Diritto costituzionale generale, Milán, 1954, pág. 204.

${ }^{30}$ Martines, Contributo a una teoria giuridica delle forze politicbe, Milán, 1957. 
Gueli ${ }^{31}$. Entre nosotros, el profesor Lucas Verdú ha aproximado a este concepto de régimen la noción teleológica de indirizzo político, a través de la idea de institución. Las instituciones son la encarnadura de las ideas políticas y un concepto básico para comprender tanto determinadas realidades jurídicas como, por ejemplo, el fenómeno extrajurídico por excelencia que es la revolución, puesto que, como ha escrito Bouthoul, «cuando las mentalidades y las instituciones se contradicen la coyuntura llega a ser revolucionaria. Nuevos valores, nuevas creencias y doctrinas se oponen a las instituciones existentes. Las revoluciones, violentas o pacíficas - nos dice este mismo autor - son, en último análisis, procesos sociales que responden a la necesidad de ajustar las instituciones a las mentalidades» ${ }^{32}$. $\mathrm{Y}$ es que, como percibió muy certeramente don Gregorio Marañón, las instituciones sociales y políticas «mueren siempre cuando, por virtud de una larga descomposición interna, sus resortes de regulación y de disciplina han dejado de funcionar. Se achaca entonces la culpa al error de los últimos dirigentes o al ímpetu de los presuntos sustitutos. Pero en realidad un régimen cuando cae es porque ha muerto antes de caer, aunque su propia pesadumbre le mantuviera en pie como el cadáver del elefante de la fábula» ${ }^{33}$.

Ahora bien, nuestra opción en pro de dar cobijo en nuestra disciplina a determinadas e importantes parcelas de la ciencia política no sólo nos facilita construir la misma en torno a las nociones claves de régimen político y de institución política, sino que muy especialmente implica una concepción valorativa de nuestra asignatura $y$, en alguna medida, el establecimiento de determinados condicionantes de cara a la elección de los métodos a emplear.

Efectivamente, si no compartimos una visión jurídico-formalista del Derecho político no es por asumir el papel político que en ocasiones ha podido desempeñar el antipositivismo a favor del cambio de determinados regímenes políticos. Sabido es, aunque no se haya profundizado aún suficientemente sobre su significado, que en la dogmática alemana de los años veinte y treinta quienes propugnan el análisis de la Constitución real por encima del mero horizonte jurídico-positivo de ordinario estaban embarcados en la lucha contra la democracia de Weimar y en el intento de restablecer en lo posible el clima monárquico-conservador de la era de Bismarck. Las andanadas de alto estilo que lanza Schmitt contra la Constitución alemana de 1919 están repletas de antipositivismo jurídico, aunque, en última instancia, no pasen de ser lo que Hesse ha denominado «positivismo sociológico determinado con sentido de futuro subyacente» ${ }^{34}$.

31 Vincenzo Gueli, Il regime politico, Roma, 1949, pág. 12. Cfr. Pablo Lucas Verdú, Introducción al Derecho político, Barcelona, 1958, pág. 114.

${ }_{32}$ Bouthoul, Sociologie de la politique, París, 1965, pág. 23.

${ }^{33}$ Gregorio Marañón Posadillo, Don Juan, Buenos Âires, 1940, pág. 132.

${ }^{34} \mathrm{Y}$ es que como escribió Francisco Ayala: «Schmitt se dedica a espiar los momentos críticos, los momentos de quiebra de la construcción del Estado de Derecho, y los denuncia para evidenciar que entonces, en el instante decisivo, el Estado constitucional traiciona sus propios principios y recae en soluciones que vienen determinadas por aquellas características inherentes y esenciales al tipo nacional de Estado que decíamos grabadas en él por el principio de poder político generador suyo: por la Monarquía. Debajo del Estado de Derecho duerme, en efecto, la Monarquía.» En su introducción a Carl Schmitt, Teoría de la Constitución, Madrid, 1934, pág. XII. 
La dimensión valorativa que creemos irrenunciable en nuestra disciplina es la que entre nosotros han propugnado, entre otros, los profesores Murillo ${ }^{35}$ y Sánchez Agesta ${ }^{36}$ como retorno de la vista hacia las viejas verdades olvidadas, pues no en vano el hombre, en cuanto libre, se rige por normas que sólo tienen sentido y resultan comprensibles cuando se relacionan con un sistema de valores. Porque, como afirmó Hauriou, la nota distintiva del hombre no está tanto en la inteligencia como en la moralidad, de modo que cabe decir, con palabras de Gaston Richard, que «la dimensión moral es una nota irreductible de la especie, aquélla de la que no pueden dar explicación las leyes de la evolución» ${ }^{37}$.

En consecuencia, habremos de intentar superar aquellas posiciones que adjetivan de metacientíficos los propósitos de construir el Derecho político desde postulados valorativos.

Así, en primer lugar, no podemos hacer nuestra la trayectoria marcada por Hegel, quien, profundizando en la ruptura que había originado Hobbes, afirmó una concepción meramente racional de la convivencia política.

Una segunda posición a superar es la aún compartida por muchos, aunque hoy habitualmente de forma inconfesada, del formalismo jurídico, en la que han militado los más infatigables paladines de una presunta objetividad científica.

En realidad, la negación de Kelsen a todo enfoque valorativo se encontraba ya larvada en Laband, quien - como ha dicho Erich Kaufmann - quiso reducir nuestra disciplina a una mera dialéctica conceptual ${ }^{38}$. Y es que Laband concebía la misión del especialista en Detecho político como la de un simple técnico, en el sentido más estricto, acaso porque, según ha escrito Otto Koellreutter, creyó que era eterno lo que se edificaba después de una guerra victoriosa ${ }^{39} . \mathrm{O}$, en última instancia, porque -como escribió Conde- estaba embarcado en la defensa del Estado prusiano frente a la invasión de la burguesía amenazadora ${ }^{40}$.

El neutralismo científico kelseniano no era tal, como se demuestra bien a las claras en su obra Esencia y valor de la democracia, y por razones aparentemente paradójicas, pero a poco que se piense demasiado obvias, ha sido muy del agrado de no pocos sistemas autoritarios, entre los que no cabe excluir a las llamadas democracias populares; así, en Vishinsky, epifenómeno jurídico-literario de Stalin, encontramos multitud de afirmaciones que bien podría haber hecho suyas Kelsen. Y es que, como con certero criterio escribió Sraffa, «la desvalorización de la obra y de la función de los juristas coincide siempre en la historia con la decadencia del pensamiento civil o con el oscure-

\footnotetext{
${ }^{35}$ Francisco Murillo Ferrol, La crisis del problema teoría-práctica de la ciencia política, en «Anuario de Filosofía del Derecho», vol. II, 1954, págs. 101-132.

${ }^{36}$ Luis Sánchez Agesta, Crisis de la politica como ciencia moral, en «Revista de Estudios Políticos», núm. 89, 1953, pág. 17.

${ }^{37}$ Gaston Richard, L'évolution des moeurs, París, 1925, introducción.

${ }^{38}$ Erich Kaufmann, Comunicación al Congreso de Juristas alemanes de Derecho público celebrado en 1928, en "Vonöffentlichungen», vol. IV.

${ }^{39}$ Otto Koellreutter, Staatsrechtswissenschaft und politik, en «S. J.Z.», septiembre, 1928, pág. 1221.

${ }^{40}$ Francisco Javier Conde, Introducción al Derecho político actual, Madrid, 1942, página 104.
} 
cimiento de las libertades políticas: cuando el método de los juristas queda reducido a una casuística fría y estéril, indigna del hombre de ciencia, y el estudio del Derecho a un aprendizaje molesto de las leyes vigentes, la sociedad por lo común o sale de una crisis o está para entrar en ella. El régimen despótico — seguía diciendo Sraffa-, aunque sea el de un Bonaparte, pide a sus escuelas que le preparen juristas que sean ejecutores, no críticos; que apliquen las leyes, pero no las juzguen» ${ }^{41}$.

Pero en nuestra disciplina, como en general en todas las ramas del Derecho, el jurista que realmente merece tal nombre, junto a la función de interpretar la norma vigente, asume la función, no menos trascendente, de criticar sus defectos y preparar una norma nueva, capaz de satisfacer mejor las necesidades sociales.

En tercer término, tampoco es compatible con el enfoque que quisiéramos que presidiese nuestra disciplina lo que alguna vez se ha dado en denominar «refinadísimo juego convencional del positivismo lógico». Nos referimos a la pretendida neutralidad valorativa que ha presidido el esfuerzo empirista de Lasswell y de sus seguidores, que, como han dicho Pinto y Grawitz, confían tan sólo en el valor de la observación y en la supeditación de la razón a la evidencia de la experimentación» ${ }^{42}$. No se trata tan sólo de que tengamos conciencia de que esta actitud ha provocado en la misma Norteamérica una fuerte reacción contra quienes, como Easton, acusan a estas actitudes de «hiperfactualismo» y de pretender hacer ciencia política sin labor de síntesis y sin construcciones sistemáticas. Sino de que no puede ser tomado demasiado en serio el neutralismo valorativo que el «behaviorismo» pregona para la sociología política, puesto que no puede ocultar que ha asumido unos valores en concreto, los valores democráticos norteamericanos, aunque no sobre una base de reflexión moral, sino como premisa de la construcción científica, y ello hasta el punto de que, con razón, haya podido decir Meynaud que «los political scientist de Estados Unidos se constituyen en el extranjero con una buena fe total, no ya en los defensores, sino en los viajantes de comercio de la democracia americana" ${ }^{43}$.

$\mathrm{Y}$ es que, aunque se utilice la vía empirista, las conclusiones de la observación estarán en función de la forma en que ésta se lleve a cabo. Con razón hizo notar Russell humorísticamente que cuando se somete a los animales a experimentación éstos se comportan «según las características racionales de sus observadores», amén de que ya Weber comprendió - como bien ha subrayado Aron- que la elección del objeto de estudio es a la postre una opción valorativa ${ }^{44}$. Pero hay más, pues no deja de ser obvia la indicación que nos hace

${ }^{41}$ Sraffa, La riforma della legislazione commerciale e la funzione dei giuristi, en «Rivista di Diritto commerciale», 1913, núm. 1, pág. 1013.

${ }_{42}$ Roger Pinto y Madeleine Grawitz, Métbodes des Sciences sociales, París, 1964, vol. I, página 323.

${ }_{43}$ Jean Meynaud, Introducción a la ciencia política, reimpr., Madrid, 1971, pág. 309. $\mathrm{Y}$ el mismo autor añade: «Hay una especie de 'mesianismo' cuyos efectos pueden ser también temibles, en inspirar a los demás pueblos, bien instituciones que no corresponden a su sistema de 'valores', bien 'valores' que resulten incompatibles con los objetivos cuya realización se pretende promover al mismo tiempo.»

4 Raymond Aron, «Introducción» a la obra de Max Weber, El politico y el científico, 
Burdeau sobre la existencia de una identidad parcial en nuestra disciplina entre el sujeto y el objeto de estudio. El observador siempre está presente de alguna forma en el espectáculo que observa. Y si pasamos de la observación a la síntesis, la eliminación del temperamento propio del investigador se hace todavía más difícil. Como ya no se exige permanecer pasivo, el espíritu contribuye con sus recursos propios ${ }^{45}$. Y en el terreno del Derecho político las valoraciones implícitas o larvadas están siempre presentes en el especialista, porque, como hace ya medio siglo advirtió sagazmente Rudolf Laun, «a un astrónomo puede perdonársele que no se ocupe de la política y que no tenga adoptada posición respecto a sus incidencias, pero sería ridículo que un profesor de Derecho político careciera de convicciones propias en lo político» ${ }^{46}$.

Si nuestra disciplina la entendemos al estilo de como Santo Tomás concebía la ciencia política, con la vista puesta en orientar la actividad del gobernante y de los gobernados en el camino hacia su finalidad propia, de un lado habremos puesto las bases adecuadas para construir un Derecho político que soslaye el riesgo que Kirchmann apuntó cuando, en frase que se haría célebre, sostuvo que «tres palabras rectificadoras del legislador bastan para convertir una biblioteca jurídica en basura ${ }^{47}$, y de otro lado podremos mirar con alguna desconfianza la etapa especulativa de nuestra ciencia, que arranca con Hobbes y no trata de suministrar orientación a las actividades políticas, sino de erigir un sistema cerrado en sí mismo, en el que cada pieza tiene sus encajes con las demás y cada proposición deriva de las otras. $\mathrm{Y}$, como el profesor Murillo ha apostillado con gracejo, «bastará un pase más para que la ciencia política se despegue totalmente de la realidad y los grandes estadistas puedan gobernar ingentes países habiendo leído los escritores políticos de la antigüedad, mientras que a su sombra se escriben toneladas de inútiles libros de ciencia política especulativa» ${ }^{48}$. Pero desde las grandes aportaciones que nos legó Heller, la esperanza en el resurgimiento de nuestra disciplina está puesta en relacionar adecuadamente las teorías con la realidad ${ }^{49}$. El esfuerzo llevado a cabo en este sentido por Friedrich ${ }^{50}$ y por Burdeau ${ }^{51}$ marca la trayectoria que deberíamos continuar en la medida de nuestras fuerzas.

3." ed., Madrid, 1972, págs. 12-13. Puede verse una acertada síntesis del curso seguido por Weber para decantar sus tesis al respecto en el artículo de Eugenio Recio Figueras, Metodología de las ciencias sociales, en «Revista Española de la Opinión Pública», núm. 34, 1973, pág. 126.

${ }_{45}$ Georges Burdeau, Método de la ciencia política, Buenos Aires, 1964, págs. 153-154.

${ }^{46}$ Rudolf Laun, Der staatsrechtsrichter und die politik, en «Arc. del öff. Rechs», vol. 43, páginas 145 y sigs. Poco tiempo después el mismo autor volvió sobre el tema en Die politische Erziebung der studierenden an den Hocbscbulen und bocbscbuläbnlichen Anstellen, en «Zeitsch f. Politik», núm. XX-II, 1931, págs. 699 y sigs.

47 J. H. Kirchmann, La jurisprudencia no es ciencia.

${ }^{48}$ Francisco Murillo Ferrol, La crisis del problema teoría-práctica de la ciencia política, en «Anuario de Filosofía del Derecho», vol. II, 1954, pág. 110.

49 Véase Gerhart Niemeyer, «Prólogo» a la obra de Herman Heller, Teoría del Estado, 5." ed., Méjico, 1963, pág. 8 .

so Carl J. Friedrich, Gobierno constitucional y democracia. Teoría y práctica en Europa y América, trad. de la 4." ed., Madrid, 1975. Véase, en especial, vol. I, págs. 29 a 91.

${ }^{51}$ Georges Burdeau, Traité de Science politique, 2." ed., París, 1966. Véase, en especial, vol. I, págs. 22 a 25. 
Consecuentes con las premisas expuestas, pensamos que en las lecciones del programa de primer curso de nuestra asignatura de Derecho político se deben abordar los temas fundamentales de una teoría jurídica de la política y, a la vez, de una teoría metajurídica de la política. Y ello sin perjuicio de una parcela del Derecho constitucional comparado, como más adelante expondremos.

Pensamos con Friedmann que la primera «función vital» que la teoría jurídica de la política tiene que colmar consistirá en «formular los ideales políticos en términos de justicia y en discurrir los medios para que esos ideales, por vía de un orden legal, se encarnen en la realidad social» ${ }^{52}$.

En segundo término, creemos que nuestra disciplina, en su vertiente jurídica, debe construir y ofrecer los diversos procedimientos de garantía de los derechos de los súbditos, deslindar competencias, organizar los diversos poderes y, a la par, prever los cauces a través de los que estos mismos poderes han de desenvolver las funciones que les están encomendadas. Por lo que creemos que la ciencia del Derecho constitucional tiene, junto a su aspecto sustantivo, lo que Gapograssi ha denominado un cierto carácter adjetivo o procesal ${ }^{53}$.

$\mathrm{Y}$ en tercer lugar, una teoría jurídica de la política ha de dotar al Estado de certeza y de seguridad - $y$ en esto no tenemos inconveniente en reconocer que tenía razón Hobbes-, porque de lo contrario carecerá no ya de legitimidad o de autoridad, sino que dejará de existir como tal Estado. Podría pensarse que este último aspecto que subrayamos de nuestra ciencia tiene una connotación conservadora, pero quizá esa función conservadora es inherente a todo Derecho o quizá, y no debe escocernos, tenía en alguna medida razón Marcel Prelot cuando decía que los profesores de Derecho somos en el fondo los más conservadores de todos los hombres.

Ahora bien, esta teoría jurídica de la política ha de construirse en todo momento con plena conciencia de la dificultad que encierra el esfuerzo de juridizar la política. Y ello, cuando menos, siguiendo a André Hauriou, por tres razones: en primer lugar, porque la violencia es en cierto sentido consustancial a la relación política. En segundo término, porque la vida política tiene, aparte de la violencia, una espontaneidad y un poder de evolución considerable. Y, finalmente, porque los preceptos del Derecho constitucional se dirigen a actores jurídicos particularmente poderosos, que no siempre obedecen las reglas establecidas ${ }^{54}$. Con su habitual perspicacia, ya llamó la atención Heller sobre la circunstancia de que las normas jurídico-constitucionales carecen por lo general del respaldo de la coacción física, aunque no por ello están privadas de auténtica condición jurídica ${ }^{55}$; pues, como sostiene acertadamente García Pelayo, lo esencial en el Derecho no es tanto la posibilidad de obligar a su cumplimiento por el empleo de la fuerza física, sino la garantía de efectividad, que puede depender de la presión impersonal ejercible sobre el destinatario de la norma

52 W. Friedmann, Legal Tbeory, Londres, 1944, pág. 418.

${ }^{53}$ Giusseppe Capograssi, Opere, Milán, 1959, vol. III, pág. 387.

${ }^{54}$ André Hauriou, Derecho constitucional e instituciones politicas, Barcelona, 1971, página 23.

${ }_{55}$ Hermann Heller, Teoría del Estado, 5." ed., Méjico, 1963, pág. 205. 
política ${ }^{56}$. Pero se suscita otra objeción, prácticamente incontestable, que dimana de que en materia constitucional no son escasas las ocasiones en que aquellas personas a quienes está confiada la tutela y observancia de las normas son a su vez las que deben obedecer los mismos preceptos constitucionales. De aquí que Prelot haya comparado tal estado de cosas con aquella famosa proeza del barón de Münchhausen, que consistía en elevarse en el aire tirando de sus propios cabellos. $Y$ es que en nuestra disciplina en muchos casos no hay respuesta técnico-jurídica a la pregunta: Quid custodet custodes? ${ }^{57}$.

Habrá que aceptar, en consecuencia, la conclusión a la que llegó Heller de que la vida política no es totalmente normativizable, pero que al menos - en el seno de un Estado de Derecho- debe aspirarse a que sea normalizable.

De otro lado, según hemos apuntado, creemos que debemos dar entrada en un programa de Derecho político a una teoría metajurídica de la política y de lo político en la línea que marcó Montesquieu, ya que, sin renunciar a su condición jurídica, no deseamos incurrir en un reduccionismo positivista de raíz ideológica.

Desde esta perspectiva, la teoría política ha de ser ante todo realista y, por ende, ha de partir de que, como escribió entre nosotros Cambó, tras una dilatada vida pública, «la política es, en esencia, la lucha para conseguir el poder y desde él convertir en realidad todo o parte - casi siempre parte- de un programa. En países regidos por instituciones democráticas, un partido no acaba la lucha cuando ha llegado al poder. Lo único que entonces hace es cambiar su posición en la lucha: pasa de la ofensiva a la defensiva, porque el partido o partidos adversos comenzarán a maniobrar para conquistar el poder ${ }^{58}$. En suma, la lucha por el poder es un denominador común a la teoría de la política tal como la concibieron numerosos autores, desde los sofistas hasta Schmitt, pasando por Maquiavelo y Hobbes. Pero creemos que esta concepción ha de ser complementada con la que insiste en la dimensión teleológica de la policía,. con la vista puesta en el bien común de la colectividad, desde Sócrates hasta Hans Barth, pasando por Aristóteles, Santo Tomás o Locke.

Una teoría política moderna tal y como la concebimos nosotros ha de partir, por supuesto, de que el conflicto no es un factor extraño, anormal o patológico que incida sobre la sana estructura del sistema, sino que es preciso coincidir con Merton en que el conflicto social es un elemento más e inevitable de la estructura social, que es perenne ${ }^{59}$, e incluso hay que reconocer la razón que asiste a Lewis Coser cuando afirma que los conflictos pueden ser funcionales, dado que pueden contribuir a la integración de los sistemas sociales ${ }^{60}$. Esta hipótesis no excluye otras ni descalifica a otras teorías basadas en diferentes premisas -el consenso, por ejemplo-, pero considera al conflicto una hipótesis de trabajo más potente y fructífera. Al fin y al cabo, como afirma Mos-

${ }^{56}$ Manuel García Pelayo, Derecbo constitucional comparado, 7. ed., Madrid, 1964, página 115.

${ }_{57}$ Marcel Prelot, Introduction à l'étude du Droit constitutionnel, en la obra colectiva Introduction à l'étude du Droit, París, 1953, vol. II, pág. 77.

${ }^{58}$ Francisco Cambó, Las dictaduras, Madrid, 1929, pág. 181.

${ }^{59}$ Robert Merton, Social Tbeory and Social Structure, 1959.

${ }^{\infty}$ Lewis Coser, Las funciones del conflicto social, Méjico, 1961. 
covici, «las colectividades sin conflictos no son utópicas: son imposibles» ${ }^{61}$. Así entendido, uno de los aspectos de un moderno Derecho político es una teoría del conflicto. Si se quiere, puede incluso denominarse como una «teoría de las borrascas, de los vendavales y de las tormentas». Es decir, una Sturmlebre, como dijera Jacobo Burckhardt.

De otro lado, el programa dedicado al primer curso de nuestra disciplina puede recoger muy fructíferamente el meollo de lo que tradicionalmente se ha dado en llamar Derecho constitucional comparado, y que hasta ahora suele venir configurando el grueso de la materia que se aborda en el segundo curso de nuestra disciplina, toda vez que con ello, de una parte, se huía -en no pocos casos- de tratar en detalle la legalidad política fundamental del franquismo y, de otra, se introducía al alumno en una fronda intrincada y espesa de regímenes jurídico-constitucionales ${ }^{62}$, cuya extensión de ordinario aparejaba una mínima profudidad en el análisis y simples exposiciones yuxtapuestas, que poco o nada tenían que ver con la metodología comparada propiamente dicha, amén de otras insuficiencias que el profesor Ramírez ha subrayado sin excesivos pelos en la lengua ${ }^{63}$.

Dejo ahora abierto el interrogante del ángulo por el que habría que optar para aproximarnos en el programa del primer curso a las grandes instituciones políticas existentes en los principales órdenes constitucionales foráneos. ¿Quizá comparando las instituciones particulares de los diferente países, pero tomando como elemento-eje de referencia las que estamos estrenando actualmente en nuestra patria, a modo y manera a como enfocó respecto de la Constitución vigente italiana en su célebre obra Biscaretti di Ruffia? ${ }^{64}{ } \mathrm{O}$ acaso es preferible el estudio del Derecho constitucional comparado, al recorrer los grandes hitos que jalonan el programa del primer curso de la disciplina, según hizo en su día el gran maestro Adolfo Posada, al abordar el estudio de la soberanía, los derechos de la personalidad, el régimen de opinión pública, los partidos políticos, el Gobierno, el sufragio, la función y los órganos legislativos, la jefatura del Estado y la función judicial? ${ }^{65} \mathrm{Y}$, por supuesto, caben también otras perspectivas más o menos clásicas o heterodoxas, en las que ahora no es momento de ahondar.

Pienso que, en todo caso, el impregnar de ciertas dosis de Derecho compa-

61 Serge Moscovici, La societé contre nature, París, 1972, pág. 84. Cfr. Nicolás Ramiro Rico, op. cit., pág. 187.

62 Sánchez Agesta, tras examinar numerosos programas de los titulares de la disciplina observó que los «tópicos clásicos que se repiten en todos los programas» son «Inglaterra, Estados Unidos, Francia, Unión Soviética, Portugal, Suiza, Alemania e Italia». En su ponencia sobre La enseñanza de la ciencia política en España, presentada en la Asociación Española de Ciencia Política, Madrid, diciembre 1959. Después, según es suficientemente conocido, se incorporaron a la práctica totalidad de los programas lecciones dedicadas a la exposición de los regímenes políticos vigentes en las democracias populares y en el Tercer Mundo.

${ }^{63}$ Manuel Ramírez Jiménez, La ciencia política en España. Problemas, métodos y áreas de estudio, en «Revista de Derecho Público», núm. 67, 1977, págs. 268-269.

${ }_{64}$ Paolo Biscaretti di Ruffia, Derecbo constitucional, Madrid, 1965.

${ }_{65}$ Adolfo Posada, Tratado de Derecbo político, 5. ${ }^{2}$ ed., con la participación de Nicolás Pérez Serrano, vol. II, Madrid, 1935, págs. 329 y sigs. Si bien ha de hacerse notar que en la primera parte de este volumen se sigue un criterio más tradicional. 
rado el primer curso puede ser fructífero, puesto que aquél contribuye a moverse en auténtico contacto con la realidad $\mathrm{y}$, por ende, puede contribuir a corregir la tendencia al formalismo y a la abstracción de la teoría jurídica y de la teoría metajurídica de la política, respectivamente.

Ahora bien, un Derecho constitucional comparado que aspire a estar dotado de un deseable realismo debe construirse a cuatro niveles distintos, a saber: el histórico (que permitirá conocer las circunstancias y motivaciones que explican la aparición de un determinado orden jurídico-constitucional), el propiamente jurídico (que posibilitará abordar desde una visión técnico-legal la estructura de las normas fundamentales), el dinámico-político (que nos permitirá conocer la influencia que en las normas constitucionales tienen los factores políticos y cuál es en la práctica el grado de vigencia que alcanzan las disposiciones fundamentales) y el ideológico (que nos facilita comparar instituciones, ateniéndonos no tanto a su homogeneidad formal como a su real significado). $\mathrm{Y}$ como todo ello ha de ser compatible con un esfuerzo notable de síntesis, no cabe afirmar que la exposición al alumno de esta parte de la asignatura sea empresa demasiado fácil.

Entre nosotros, el profesor Ramiro Rico, haciendo sin duda referencia a las comparaciones que en ocasiones se establecen desde bases meramente aparenciales, escribió socarronamente que el «Derecho constitucional comparado es una enseñanza en gran parte imaginaria, donde reina supremo el quiproquo, pues se quieren comparar regímenes de mejor o peor funcionamiento práctico en el país de origen, con sus espectales remedos e imitaciones en el país receptor. En los Estados Unidos, por ejemplo, uno que otro general ha llegado a presidente por la vía constitucional del sufragio, mientras que en la Argentina, sea otro ejemplo, los generales derrocan casi habitualmente a los presidentes electivos, y suplen el vacío político así creado como Dios les da a entender. No hay mucho que comparar - concluye Ramiro Rico- si somos sinceros» ${ }^{66}$.

Realmente la construcción de un moderno y sensato Derecho constitucional comparado no es tarea fácil, porque la política, como dijo Campanella, «scientia est de singularibus», y como decía con cauto criterio Laski: «Uno de los peligros principales a la hora de estudiar la política radica en los intentos de elaborar amplias generalizaciones, que nacen de la comparación de órdenes distintos.» $\mathrm{Y}$ aún cabe recordar otra importante llamada a la prudencia, la de Luzzatti, quien afirmó, con frase gráfica, que «los pueblos no son como placas fotográficas, que a la acción del mismo rayo luminoso de un sistema político tengan que dar idéntica imagen» 67 .

No obstante, creemos que el valor didáctico de unas dosis razonables de Derecho constitucional comparado es tan alto que bien se justifica el esfuerzo que supone su construcción ${ }^{68}$. Pensamos que en la hora actual buena parte de

"6 Nicolás Ramiro Rico, Breves apuntes críticos para un futuro programa moderadamente beterodoxo del Derecbo politico $y$ de su muy azorante enseñanza, en «Revista de la Opinión Pública», núm. 37, 1974, pág. 186.

${ }_{67}$ Luzzatti, I metodi nello studio del Diritto costituzionale, en «Nueva Antología», 6." serie, vol. 222, pág. 201.

${ }_{68}$ En análogo sentido, véase, Luis Sánchez Agesta, Curso de Derecho constitucional comparado, 5." ed., Madrid, 1973, pág. 22. Y también, Pablo Lucas Verdú, Consideracio- 
tal esfuerzo ha de dirigirse a adaptar a nuestra disciplina, en la medida de lo posible, los logros alcanzados por lo que modernamente los anglosajones han denominado Comparative Politics. Desde este ángulo, creemos que es preciso prestar especial atención a lo que Blondel denomina interconexión entre normas, instituciones y conductas ${ }^{69}$. Y además el análisis comparativo, si aspira a estar dotado de una mínima exactitud, ha de observar y sopesar el gran número de variables que entran en la configuración de un sistema político. Ello nos pone en la pista de que la tarea -en el campo de un curso propedéutico en una licenciatura de Derecho-, de puro ambiciosa, raya en lo inabordable, mientras que en el terreno de la investigación científica habrá que reconocer que difícilmente un especialista en nuestra materia puede llegar a dominar el alto número de factores heterogéneos que intervienen en la explicación de un sistema político, desde las condiciones económicas y sociales hasta el clima o la geografía física. La necesidad de la investigación asociada, que permite disponer de especialistas en ciencias auxiliares a la nuestra, va a ser cada día más notoria. Las explicaciones por una sola variable, en nuestra opinión, han de ser descartadas, tanto si provienen del campo del formalismo juridicista como si - según hoy es más frecuente- se trata de explicaciones marxistas o neomarxistas, que tienen sin duda un cierto valor explicativo a un nivel muy general, pero que no permiten estudios comparativos dotados del rigor a que hemos de aspirar.

De otra parte, pensamos que el programa del segundo curso de nuestra asignatura debe abordar, como no podría por menos de ser, la historia del constitucionalismo español y la normativa fundamental hoy vigente. $\mathrm{Y}$ lo ha de hacer con la mayor amplitud y profundidad posibles.

Sin duda, nuestra disciplina, en evitación del etnocentrismo y del riesgo que Unamuno definía como el caer en sueño hipnótico por no mirar sino al propio ombligo, puede y debe ser cosmopolita y no aldeana. El contraste posible entre la pluralidad de autores suministra una imprescindible base de partida, como bien observó Popper ${ }^{70}$, en la búsqueda de la difícil objetividad. Realmente no cabe en nuestra disciplina el nacionalismo científico, del que ya se reía sutilmente Jellinek cuando decía que era tan absurdo como querer construir de modo científico una ética francesa o una anatomía británica.

Pero esto no significa que un teoría política que pudiéramos denominar universal no pueda afrontar como objeto especial de estudio la historia y la realidad constitucional y dinámico-política española; y, por supuesto, la misma encierra aspectos tan singulares en su evolución que no tenemos inconveniente en llamar la atención sobre la necesidad de nacionalizar nuestra ciencia, en la medida en que la misma debe tomar como objeto fundamental de estudio nuestra atormentada histórica constitucional y nuestra, aún en proceso in fieri, nueva legalidad política.

Los estudios generales y las monografías sobre la historia constitucional

nes en torno al concepto, método y funciones del Derecho constitucional comparado, en «Boletín Informativo del Seminario de Derecho político», núm. 6, Salamanca, 1955, pág. 88.

${ }^{69}$ Jean Blondel, Introducción al estudio comparativo de los gobiernos, Madrid, 1972, páginas 26-29.

${ }_{70}$ Karl R. Popper, La miseria del bistoricismo, Madrid, 1973. 
española son aún tremendamente escasos entre nuestra bibliografía científica, y otro tanto cabe decir de las monografías publicadas en este ámbito. Recientemente me permití apuntar ${ }^{71}$ que tal estado de cosas probablemente se debe en alguna medida a que en la historia contemporánea de España han escaseado los grandes debates jurídico-políticos, el calor de contiendas políticas. Ello nos ha situado ya de entrada en inferioridad de condiciones con la literatura iuspublicista de otros países. Así, por ejemplo, en Alemania las mejores plumas en el campo de nuestra disciplina, desde Pufendorf, Leibnitz, Thomasius y Peter Ludewig hasta Piitter, han tomado parte con ardor en los problemas políticos más importantes desde los tiempos de Luis de Baviera. Y lo mismo han hecho los autores alemanes del siglo XIX, desde Klüber hasta Hermann Schulze, desde Welcker hasta Hänel y el mismo Laband, que no despreció el tomar posición en polémicos escritos sobre problemas políticos del momento con significación jurídica, como el litigio sobre el trono de Lippe o la introducción de impuestos imperiales directos.

Sin embargo, en nuestra patria los especialistas, salvo contadísimas excepciones (la mayor parte de las cuales se registran en la primera mitad del siglo XIX), han mantenido su obra a cierta distancia de los problemas políticos más importantes con que se ha enfrentado el país, lo que no sé si ha podido ir en beneficio de la difícil objetividad científica, pero desde luego ha facilitado la existencia de grandes lagunas en nuestra bibliografía, incluso en su vertiente más técnico-jurídica. Recuérdense las lamentaciones de Pérez Serrano porque no se hubiese dedicado ni un solo estudio monográfico a la Constitución de 1876, que rigió durante toda la Restauración.

Asimismo, urge profundizar en el estudio de nuestra legalidad política vigente. Resultaría, a mi juicio, hoy insostenible el que la actividad científica de nuestros especialistas en Derecho político permaneciese al margen de la dura y urgente tarea de volcar las necesarias atenciones doctrinales sobre la Constitución de 1978 y las normas de muy diverso rango, a través de las cuales se ha de producir su desarrollo. Si, de una parte, este es un momento que reclama monografías, tratados y comentarios que arrojen luz tanto sobre el alcance de estas disposiciones de nuevo cuño como sobre su interconexión con la dinámica social, de otra, estamos abocados a, superando la inercia, clausurar la práctica que se generalizó durante todos estos últimos lustros ante el carácter meramente nominal o semántico - según se quiera- de las leyes políticas fundamentales del franquismo de reducir al mínimo la exposición didáctica al alumnado de tal normatividad. Dicho en términos más breves, creo que el grueso de la asignatura, que en los planes de estudio de las facultades de Derecho se rotula Derecho Político II, ha de centrarse en el Derecho constitucional vigente. $\mathrm{Y}$ entiendo que ello ha de hacerse sin abandonar una cierta perspectiva jurídica tradicional, que nos invita a integrar el estudio de los nuevos enunciados constitucionales con las normas que los complementan (entre otras, como es obvio, leyes reguladoras del ejercicio de los derechos fundamentales, derecho electoral, derecho parlamentario...), y a la par, y por ser

${ }^{7}$ Oscar Alzaga Villaamil, La Constitución española de 1978 (comentario sistemático), Madrid, 1978, pág. 12. 
fundamental no prescindir nunca en nuestra asignatura de la consideración axiológica, estimo indispensable analizar nuestra legalidad política fundamental sin perder de vista los fundamentos de su legitimación, sus fines proclamados y los derechos a cuyo servicio está.

El que el segundo curso de nuestra disciplina - en el seno, repito, de una facultad que aspira a formar hombres de leyes - reciba el enfoque que ha quedado apuntado me parece, sin embargo, que ha de ser compatibilizado con que los profesores de Derecho político en España hagamos frente al reto de experimentar los modernos instrumentos metodológicos creados por la más moderna ciencia política en el campo de la problemática de la realidad políticohistórica y actual de España. Pensamos que en un país que ha sufrido no pocos bandazos entre los polos de tradición y modernización hay que afrontar la difícil indagación de dónde estaba y dónde está lo que Linz ha dado en llamar «el punto de equilibrio entre continuidad y renovación de la élite y el óptimo entre tradición y modernización». No parece dudoso, por otra parte, que el enfoque funcionalista facilitaría la comprensión de la incapacidad que han acreditado tantos sistemas políticos que ha conocido nuestra historia contemporánea para que los españoles se considerasen mínimamente integrados en los mismos. Y la teoría general de sistemas ofrece un campo anchísimo al estudio de cómo nuestros sistemas políticos han sido objeto de numerosas demandas sociales que no han podido satisfacer. Podríamos continuar el abocetamiento de este cuadro, pero nos parece innecesario, toda vez que lo que poco más atrás denominábamos, según la terminología de Burckhardt, «teoría de las borrascas» tiene obviamente uno de sus campos más sugestivos en la historia y en el presente de esta dura tierra nuestra.

La conclusiones que alcancemos en el esfuerzo que desarrollemos en esta trayectoria no sólo nos resultarán del mayor valor para construir una teoría metajurídica de la política adaptada al tiempo y al espacio en que hemos de desenvolvernos, y para no salirnos nunca del difícil terreno del realismo jurídico, sino que además pueden encontrar su natural cauce de exposición didáctica en asignaturas altamente análogas a la nuestra que se imparten en las facultades de Ciencias Económicas y Políticas.

Por lo demás, los enfoques apuntados no implican contradicción alguna, aunque sí el procurar superar la contraposición célebre que no ha mucho ha subrayado Pedro de Vega entre, de una parte, la posición de Rousseau, cuando en su Contrato Social escribió: «Yo busco la razón y el Derecho, y no busco los hechos», y, de otra, la afirmación de Montesquieu, en el Espíritu de las Leyes: "Aquí se dice lo que es y lo que debe ser» ${ }^{72}$. Y, si a la par, creemos con Jellinek que constituye grave falta metodológica querer aplicar a una esfera de conocimientos la manera especial que resultaba adecuada para investigaciones de un sector diferente, habremos de concluir que nuestra concepción de la asignatura, en las diversas dimensiones apuntadas, condiciona las rutas para llegar a esta realidad y las perspectivas para contemplarla, que habrán de ser también — como ha expuesto Juan Ferrando en sus trabajos sobre meto-

72 Pedro de Vega, Ciencia política e ideología, en «Boletín Informativo de Ciencia Política», núm. 3, 1970, pág. 87 . 
dología de la ciencia política- plurales. En este sentido se nos antoja afortunada la imagen que nos describe Van Dyke de la política, cuando nos dice que es como «el centro de un círculo, al que se puede llegar desde cualquier punto del mismo, con un enfoque para cada uno de los 360 grados del círculo» ${ }^{73}$.

Por supuesto, en el estudio del Derecho constitucional habrá de desempeñar un papel primordial la metodología jurídica, indispensable en la determinación de soluciones «latentes» en el propio ordenamiento, cobertura de lagunas legales, superación de antinomias normativas y, en general, para poder practicar una típica interpretación técnico-jurídica de la legalidad política. Pero como no compartimos la tesis de Kelsen de que «lo jurídico puede ser comprendido solamente a partir de lo jurídico» y tememos el quedarnos en el plano puramente exegético de las normas constitucionales, estimamos imprescindible el empleo de métodos extrajurídicos que permitan escudriñar el funcionamiento real de las instituciones que encontramos en las normas constitucionales en el contexto de la vida pública, lo que permitirá, en suma, una visión crítica del Derecho constitucional, centrada en la vigencia o inaplicabilidad real de las reglas fundamentales en el plano de la vida cotidiana.

$Y$ en cuanto al estudio de aquellos fenómenos que analiza la ciencia política, y a los que damos entrada con las salvedades apuntadas en nuestra concepción del Derecho político, basta asomarse a la obra de Butler para comprender que no puede ser más amplio el abanico de métodos utilizables ${ }^{74}$, hasta el punto de que David Easton haya opinado que esta mayor utilización de métodos por la ciencia política constituye una de las grandes manifestaciones de la revolución teorética, iniciada en el seno de la ciencia política al término de la segunda guerra mundial.

Buena parte de estos métodos que han de ser utilizados en la constitución de un moderno Derecho político proviene de otras ciencias sociales, como la psicología o la sociología, e incluso de las técnicas gráficas o matemáticas, de la teoría de las comunicaciones y de la cibernética. En estos casos el acudir a la investigación asociada es ineludible, porque hoy por ser consciente de las limitaciones de un especialista en Derecho político, aunque empecemos a temer que la amenaza cordial que lanzó hace algunos años Sawer en términos de boutade, se está cumpliendo, al menos en parte. En efecto, decía que todo abogado y juez ha presumido hasta ahora de ser su propio sociólogo, pero en el futuro «quizá también tengan que aprender a contar» ${ }^{75}$. Y, por supuesto, en todo caso sobre los métodos a emplear en nuestra disciplina hemos de tener siempre muy presente el terreno en que resulta eficaz su empleo, cuestión ésta no baladí, pues, como decía Dilthey, «los métodos son como los cuchillos, su eficacia se demuestra cortando» ${ }^{76}$. Y algunos, pese a que estén entre nosotros en la cumbre de la moda, andan muy mal de filo a la hora de la verdad.

Desearíamos terminar este artículo con algunas consideraciones en torno

${ }^{73}$ Vernon Van Dyke, Ciencia política. Un análisis filosófico, Madrid, 1962, pág. 130.

${ }^{74}$ D. E. Butler, Estudio del compartimiento político, Madrid, 1964.

${ }_{75}$ G. Sawer, Law in Society. Cfr. W. I. M. Mackenzie, Politica y ciencia social, Madrid, 1972, pág. 73.

${ }_{76}$ Wilhelm Dilthey, Psicología y teoría del conocimiento, Méjico, 1945. 
a la metodología didáctica que, aunque puedan parecer obvias por desprenderse de los meros dictados del buen sentido, me parecen casi imprescindibles para acabar de abocetar, como vislumbro, el nuevo enfoque de nuestra disciplina que entre todos hemos de emprender.

Obviamente, no son sostenibles hoy las pautas que pregonaba en 1893 el que fue gran maestro de nuestra disciplina, don Enrique Gil y Robles. Para él, la clave de la buena enseñanza radicaba en el empleo de un método dogmático y en el trato paternalista al alumno, como si de un niño se tratase ${ }^{7}$. En nuestra opinión, hay sólo un aspecto parcial de esta didáctica tradicional que ha de ser salvado. A saber: el de que al alumno se le deben facilitar los resultados científicos de una investigación ya realizada, porque sería utópico el pretender que los estudiantes hiciesen de por sî la inmensa labor que han requerido los trabajos científicos con que se ha alcanzado el nivel de conclusiones en que se encuentra hoy nuestra disciplina. Tal situación ha de ser conocida, tan ampliamente como sea posible, por el profesor, que, como recordaba Ortega, tiene por primera misión exponerla en forma sintética y razonada a su alumnado. Ortega llegaba incluso a sostener que ésta era la gran tarea del profesor, y no la investigación científica, que «no pertenece de una manera inmediata y constitutiva a las funciones primarias de la Universidad ni tiene que ver sin más ni más con ellas». Decía asimismo, con su fina ironía, que «es lo más probable que sobre esta opinión heterodoxa caiga el diluvio de tonterías que sobre cualquier asunto amenaza siempre desde el horizonte torrencial como panza de nube gordas ${ }^{78}$.

Ahora bien, el que sea imprescindible esa función expositiva no quiere decir que se trate de imponer autoritariamente criterios y opiniones personales, que en forma pasiva, sumisa e incluso inerte haya de recoger el alumno que aspira a superar la asignatura. Cuanto hemos expuesto sobre la naturaleza valorativa de nuestra disciplina implica que, en nuestro criterio, el profesor tiene el deber y la responsabilidad de exponer su concepción personal, pero que, a su vez, debe explicar análogamente otras visiones de la cuestión de que se trata, para que los escolares puedan formar debidamente sus convicciones.

Lo anterior tiene una segunda vertiente de no escasa importancia: la de que se debe exigir del estudiante una intervención personal y activa ante los temas objeto de estudio. El Derecho político no se asimila, ni siquiera al nivel de un curso propedéutico, sin un esfuerzo razonable del propio alumno. Así se lograrán conocimientos que no sean mera impronta debida a simple transmisión ajena, sino fruto de una labor conjunta del docente y de los discentes.

$Y$ el profesor no sólo debe comunicar los conocimientos acumulados por su ciencia, sino también los aspectos que se desconocen o las cuestiones sobre las que se ha abierto debate sin haberse podido llegar aún a conclusiones más o menos precisas. En este sentido es muy ilustrativa una anécdota que en alguna ocasión ha relatado Zubiri relativa a Husserl. Un día los alumnos de éste vieron a la puerta del aula un anuncio que decía así: «El profesor Husserl comunica a sus alumnos que hoy no podrá dar su clase porque no ha terminado de ver

$\pi$ Enrique Gil y Robles, Ensayo de metodología jurídica, Salamanca, 1893, pág. 28.

${ }^{78}$ José Ortega y Gasset, Misión de la Universidad, 5. ${ }^{2}$ ed., Madrid, 1965, pág. 49. 
claramente el tema que les había explicado.» En su curso, el gran filósofo se movía esforzada y arriesgadamente, sin temor al desprestigio, en el límite que separa $-\mathrm{y}$ a la vez une entre sí- el saber y la ignorancia ${ }^{79}$. Pero imagínese la «chacota» que entre estudiantes y profesores levantaría en cualquier Universidad española un letrero semejante.

Por supuesto, no se trata de infravalorar y postergar la enseñanza de saberes; sólo trato de apuntar que entre nosotros es viciosamente escasa la enseñanza universitaria de ignorancias y problemas, que no debe ser descuidada, porque de ellas nace la vocación investigadora.

A tal fin, aparte de la obligada explicación de todos los problemas básicos de la disciplina, es precisa una constante labor de orientación bibliográfica hacia obras adecuadas, el encauzamiento del alumno para que se ponga en contacto directo con los textos clásicos e igualmente enfrentar -hoy más que nunca- al alumno con la realidad de la legislación política mediante casos prácticos: aunque el case system no sea en nuestra patria tan inexcusable como en los países de Judge-made law.

Por supuesto, la masificación por que atraviesa nuestra Universidad dificulta al máximo el que el estudiante desempeñe un papel activo. Como solución de emergencia, más o menos desesperada, sabemos por experiencia que un buen recurso consiste en prestar atención especialísima al núcleo reducido de los que demuestran un especial interés por la disciplina, para los que se debe preparar un seminario monográfico, bien sobre algún tema de la historia constitucional española, que suele ser campo que a la vez despierta la viva curiosidad de los estudiantes y ofrece innumerables temas de carácter monográfico susceptibles de selección, bien sobre algún aspecto de nuestro nuevo régimen constitucional que, entre otros, ofrece sin duda el aliciente de la actualidad, o bien sobre algún estudio comparativo, pues compartimos plenamente la confianza que en el método comparado tenía Dorado Montero para que el estudioso extraiga un criterio ecuánime ${ }^{80}$, quizá porque, como señalaba Luzzati, la historia comparada de las instituciones políticas representativas refuerza el sentimiento de libertad, aconseja las transacciones y es, en suma, altamente formativa para la convivencia política ${ }^{81}$.

Sin duda, el nuevo orden jurídico-constitucional y los cambios introducidos desde un tiempo a esta parte en el plano de la realidad política española bien merecen que los profesores de nuestra asignatura nos esforcemos ilusionadamente por enfocar de nuevo la vieja disciplina del Derecho político en beneficio, sobre todo, de la formación de las nuevas generaciones de universitarios.

79 Cfr. Pedro Laín Entralgo, El problema de la Universidad, Madrid, 1968, pág. 73.

* Pedro Dorado Montero, El Derecbo racional y el bistórico, en «Revista de Legislación y Jurisprudencia», vol. 103, pág. 478.

${ }_{81}$ Luzzatti, I metodi nello studio del Diritto costituzionale, en «Nuova antologia», 6." serie, vol. 222, 1922, pág. 205. 